\title{
Effect of High Intensity Interval Training on Blood Glucose Levels in Type 2 Diabetes
}

\author{
SALMA EL SHEIKH, M.Sc.*; HEBA A. ABDEEN, Ph.D.* and MARY W. FAWZY, M.D.** \\ The Departments of Physical Therapy for Cardiovascular, Respiratory Disorders and Geriatrics, \\ Faculty of Physical Therapy* and Internal Medicine, Faculty of Medicine**, Cairo University
}

\begin{abstract}
Background: Patients with type 2 diabetes are at significantly increased risk for cardiovascular morbidity and mortality compared with age-matched healthy control subjects.

Aim of Study: Was to determine the effect of high intensity interval training on blood glucose levels in type 2 diabetes.

Subject and Methods: Forty diabetic patients of both sexes (12 males and 28 females). They were assigned into two groups equal in number. All patients were diagnosed clinically with established T2DM for more than 7-year duration. Their ages ranged from 45 to 55 years selected from outpatient clinic of Kasr El-Aini, Cairo University, Egypt. Study group with mean age (51.07 \pm 3.31$)$ years. and Control group with mean age $(51.36 \pm 2.83)$ years. The study group included 20 patients ( 7 males and 13 females) who practiced high intensity interval training at intensity level of (85-90\% of MHR), three times per week for 12 weeks in addition to their optimized oral hypoglycemic medications. Symptom limited exercise test was performed before and after training (12 weeks) to determine maximum heart rate. The control group included 20 patients ( 5 males 15 females) who only received their optimized oral hypoglycemic medications. Fasting and post prandial blood glucose were measured initially before starting the treatment and after the end of the sessions in both groups.
\end{abstract}

Results: Post-treatment there were a significant improvement in both fating and two hours post prandial blood glucose. There were a significant decrease in fasting and two hours post prandial blood glucose.

Conclusion: The high intensity interval training is an effective tool to decrease insulin resistance and hyperglycemia this effect is mediated, in part, by the decrease in fasting and two hours post prandial blood glucose in type 2 diabetic patients which consequently helps in the treatment type 2 diabetes.

Key Words: Type 2 diabetes - High intensity interval training - Blood glucose.

Correspondence to: Dr. Salma E.M. El-Sheikh, E-Mail: selsheikh25@yahoo.com

\section{Introduction}

DIABETES is the most common endocrine disorder. It is a characterized by chronic hyperglycemia, which affects the various body systems of the individual and reduces longevity, and a major cause of death in the industrialized world, causing 1.5 million deaths in 2012 [1].

Type 2 Diabetes Mellitus (T2DM) results from an interaction between genetic and environmental factors. Genes and the environment together are important determinants of insulin resistance and $\beta$-cell dysfunction. Because changes in the gene pool cannot account for the rapid increase in prevalence of T2DM in recent decades, environmental changes are essential to the understanding of the epidemic [2].

Diabetes is increasing worldwide and this development is expected to continue: In Europe, diabetes prevalence has been projected to rise from $8.5 \%$ (2013) to $10.3 \%$ (2035) in adults $20-79$ years, as a consequence of the aging population. However, if incidence of diabetes is rising as well, this forecast is an underestimation. Changes in survival in patients with diabetes will also affect the future burden of diabetes. A rise in the number of diabetes patients will have a major impact on public health since diabetes is afflicted with a range of comorbidities including an increased risk of cardiovascular disease and premature death. It will also have consequences for public spending and planning of health care services [3].

Regular exercise with metabolic control in people with diabetes can control blood sugar levels and amplify defensive responses of the body. Ex- 
ercise plays an essential role in control of diabetes, and in addition to strengthening muscles and maintaining health of the heart, blood vessels, exercise affects the entire immune system, and change in immune parameters [4]

It has been previously established that secondary to sustained hyperglycaemia in diabetes, persistent low-grade inflammatory processes resulting from increased cytokine expression leads to cellular insult, tissue injury and functional impairments [5].

It is known that exercise is a safe, nonpharmacological and cost-effective strategy to prevent the development of most diseases, to slow down their progression, but also to provide benefits in patients affected by chronic diseases [6]

High Intensity Interval Training (HIIT), which consists of brief repeated bursts of relatively intense exercise separated by periods of recovery, is a time efficient strategy to induce physiological adaptations similar to endurance training. It is tempting to speculate that HIIT increased skeletal muscle insulin sensitivity. The high degree of muscle fiber recruitment and/or glycogen utilization associated with HIT may increase subsequent muscle glucose uptake [7].

High intensity interval training involves alternating between short periods of higher and lowerintensity exercise. High-intensity interval training leads to greater gains in cardiorespiratory fitness in people with or without diabetes, and improves glycemic control in some studies of people with type 2 diabetes compared to continuous moderateintensity exercise [8].

Exercise, including aerobic exercise, endurance type exercise, passive exercise and resistance exercise are fundamental therapeutic effects towards T2DM. Effect of aerobic exercise in T2DM Aerobic exercise is the exercise which improves oxygen consumption and increases the functioning of the cardiovascular and respiratory systems. Aerobic exercise is a valuable therapeutic strategy for T2DM as it has beneficial effects on physiological parameters and reduces the metabolic risk factors in insulin resistance diabetes mellitus [9].

The intensity of an exercise routine is often viewed as a main determinant of subsequent improvements in glycemic control. Given the proposed relationship between the degree of glycogen depletion and subsequent improvements in insulin sensitivity, many exercise guidelines advocate endurance exercise at vigorous intensities to maximize endogenous glycogen use and increase the impact of exercise on glycemic control. Although some studies have found superior benefits of highintensity as opposed to moderate-intensity endurance-type exercise on insulin sensitivity [10].

\section{Subjects and Methods}

Subjects: Forty patients of both sexes (12 male and 28 female) with type 2 diabetes since 7 years, aging from 45-55 years old. They were selected from outpatient clinic of Kasr El-Aini, Cairo University, Egypt. All patients were investigated and diagnosed by internist. They were received their treatment program from August to November 2019 and the following laboratory tests were done for both groups: Fasting and post prandial blood glucose. These variables were measured initially before starting the treatment and after the end of the sessions in both groups. The study duration was 12 weeks.

Inclusion criteria: All patients were diagnosed clinically with established T2DM for more than 7-year duration, treatment only with oral hypoglycemic agents. Their age ranges from 45 to 55 years old of both sexes. Body mass index range (30-39) $\mathrm{kg} / \mathrm{m}^{2}$.

Exclusion criteria: Patients with these diseases were excluded from the study: Uncotrolled diabetes, unstable cardio/respiratory condition, such as uncontrolled hypertension, cardiovascular accident or myocardial infarction within the last 2 months, surgery within 6 weeks of enrolment, severe retinopathy, neuropathy, visual problems not corrected, nephropathy, patients who had scars under their feet. Severe musculoskeletal problems restricting physical activity.

Randomization: The participants were randomly assigned to group (A) $(n=20)$ or group (B) $(n=20)$ by an independent person who selected blindly from sealed envelopes containing numbers created by a random number generator. The randomization was restricted to permuted blocks to ensure that equal numbers were allocated to each group $\mathrm{A}$ and group $\mathrm{B}$. The sequences assigned to the participants were placed in envelopes containing the allocation to each group A and group B.

The aim and procedures of the study were informed to eligible patients. All patients signed a written informed consent. The study was approved by the Ethical Committee of Faculty of Physical 
Therapy, Cairo University. It was obtained before the study by No. P.T.REC/012/002363.

The patients were randomly assigned into two equal groups, group (A), and group (B).

- Group (A): It included 20 patients who was received high intensity interval training program for 12 weeks ( 3 sessions/week) in addition to their optimized oral hypoglycemic medications.

- Group (B): It included 20 patients who was received their optimized oral hypoglycemic medications.

Evaluation: Every patient was assessed by a physician to select eligible patients. Before patient inclusion in this study, a complete medical history and drug history were used for the patients. All tests were performed before the sessions (pre-) and after (post-) sessions period for each participant including Laboratory tests to measure fasting blood glucose and two hours post prandial blood glucose.

Symptom limited exercise test: Was performed before and after training (12 weeks) to determine maximum heart rate. [1] Maximum HR was determined as participants performed an incremental cycling increasing $1 \mathrm{~W}$ every $2 \mathrm{~s}$ while being monitored using the telemetry until reaching the symptom-limiting exercise; then, the maximum HR was recorded.

Lab analysis: The Erba Chem 7 which is the new generation Clinical Chemistry analyser, designed compactly. It is used for analyzing fasting blood glucose and post prandial blood glucose before and after 12 weeks of training.

\section{Guide lines and precautions:}

Before starting any HIIT program, all patients were able to exercise for at least 20-30 minutes at $70-85 \%$ of their previously measured maximum heart rate, without exhaustion. The patients performed warm up and cool down for at least five minutes before and after each HIIT session. The patients worked as hard as they can during the high intensity intervals, until they feel pain in their muscles indicating that they have entered his anaerobic zone. If they experience any chest pain or breathing difficulties during the HIIT workout, cool down immediately done. If the heart rate does not drop back down to about $70 \%$ of the max during recovery intervals, we may need to shorten the work intervals and/or lengthen the recovery intervals.

\section{HIIT program:}

Mode: Cycling on a stationary bicycle (Stairmaster Spinnaker 3700 Recumbent), duration: $20-$ 30min (total session), frequency: 3 times/week (day after day), intensity: High intensity (85-95\% MHR since HRmax varies by individual, and recovery at (60-70\% MHR).

\section{Training heart rate was calculated as follow:}

Training heart rate $=85-95 \%$ (maximum heart rate-resting heart rate) + resting heart rate, for high intensity.

Training heart rate $=60-70 \%$ (maximum heart rate-resting heart rate) + resting heart rate, for recovery.

All participants were instructed not to change their dietary or lifestyle.

\section{Exercise protocol:}

The HIIT protocol involved 10 X 60s cycling efforts interspersed with 60 s of rest. Exercise was performed on a stationary bicycle. A 5-min warmup and 5-min cool-down were included [11].

\section{Statistical analysis:}

In this study, the descriptive statistics (the mean, the standard deviation, maximum, minimum and range) were calculated for all patients of the study including fasting and post prandial blood glucose. Comparison was made by $t$-test to compare the variables between both stages of the study. Paired $t$-test was done to compare the differences between fasting and post prandial blood glucose before and after treatment.

Unpaired $t$-test will be done to compare the differences betweenresults of fasting and post prandial blood glucose before and after treatment between study and control groups.

Level of significance: The threshold of significance was fixed of 0.05 ( $p$-value). A $p$-value $>0.05$ indicates non-significant results. A $p$-value $<0.05$ indicates significant results. The smaller the $p$ value obtained, the more significant is the result.

\section{Results}

I- Descriptive analysis of the anthropometric measures (age, height, weight and BMI) of all the subjects: The mean age, weight and height of all the subjects participating in this study ( 20 patients in the study group and 20 patients in the control group) are listed in (Table 1). There was no significant difference between both groups in the mean age, weight, height, and BMI $(p>0.05)$. 
Table (1): Descriptive statistics and $t$-test of the mean age, weight, height, and BMI of study and control groups.

\begin{tabular}{lccccc}
\hline \multirow{2}{*}{ Variables } & \multirow{2}{*}{$\begin{array}{c}\text { Control group } \\
\text { Mean } \pm \text { S.D }\end{array}$} & $\begin{array}{c}\text { Study group } \\
\text { Mean } \pm \text { S.D }\end{array}$ & \multicolumn{2}{c}{ Comparison } & \multirow{2}{*}{ Significance } \\
\cline { 4 - 5 } & & & $t$-value & $p$-value & \\
\hline Age (years) & $51.36 \pm 2.83$ & $51.07 \pm 3.31$ & -0.270 & 0.789 & N.S \\
Weight (K.g.) & $86.45 \pm 3.83$ & $87.82 \pm 4.87$ & -0.729 & 0.475 & N.S \\
Height (Cm.) & $162.27 \pm 5.06$ & $162.72 \pm 4.94$ & -0.591 & 0.561 & N.S \\
BMI & $32.94 \pm 2.82$ & $33.31 \pm 3.55$ & -0.272 & 0.787 & N.S \\
\hline N.S : Non Significant. & $p:$ Probability value. & & \\
S.D : Standard Deviation. & $t: t$-test. & & &
\end{tabular}

II- Comparison between the mean values of all variables of the study (fasting blood glucose and post prandial blood glucose) before and after treatment in the two groups (study and control): From the data listed in (Table 2) we can see that there was a significant decrease in in study group posttreatment compared with pre-treatment, while there was non significant decrease in fasting blood glucose and post prandial blood glucose in control group post-treatment compared with pre-treatment.

Table (2): $t$-test of comparison between pre and post-treatment mean values of fasting and post prandial blood glucose of both groups (study and control).

\begin{tabular}{lllllr}
\hline & \multicolumn{5}{c}{ Study group } \\
\cline { 2 - 6 } & \multicolumn{1}{c}{ Pre-ttt } & Pos-ttt & t-value & $p$-value & $\begin{array}{c}\% \text { of } \\
\text { improvement }\end{array}$ \\
\hline Fasting blood glucose & $243.90 \pm 8.13$ & $200.81 \pm 8.60$ & 22.40 & $0.0001 *$ & $\downarrow 17.66 \%$ \\
Post prandil blood glucose & $364.27 \pm 41.04$ & $321.18 \pm 33.50$ & 3.97 & 0.0026 & $\downarrow 11.82 \%$ \\
\hline
\end{tabular}

Table (3): $t$-test of comparison between pre and post-treatment mean values of fasting and post prandial blood glucose of both groups (study and control).

\begin{tabular}{lccccc}
\hline & \multicolumn{5}{c}{ Control group } \\
\cline { 2 - 6 } & \multicolumn{1}{c}{ Pre-ttt } & Pos-ttt & $t$-value & $p$-value & $\begin{array}{c}\% \text { of } \\
\text { improvement }\end{array}$ \\
\hline Fasting blood glucose & $244.09 \pm 6.92$ & $243.18 \pm 7.60$ & 1.022 & 0.33 & $\downarrow 0.37 \%$ \\
Post prandil blood glucose & $360.90 \pm 35.69$ & $361.81 \pm 35.14$ & -0.77 & 0.48 & $\downarrow 0.25 \%$ \\
\hline
\end{tabular}

III- Comparison between control group and study group in both pre-treatment and posttreatment. Values of (fasting and post prandial blood glucose): From the data listed in (Table 3) we can see that there was no significant difference in the mean values of fasting and post prandial blood glucose between both groups (study and control) pre-treatment, while comparison between the study and control groups post-treatment showed a significant decrease in the mean values of fasting and post prandial blood glucose of the study group compared with the control group.

Table (4): $t$-test of comparison between study and control groups in both pre and post treatment, mean values of (Fasting and post prandial blood glucose).

\begin{tabular}{|c|c|c|c|c|c|c|c|c|}
\hline & \multicolumn{4}{|c|}{ Pre-treatment } & \multicolumn{4}{|c|}{ Post-treatment } \\
\hline & $\begin{array}{c}\text { Study GP } \\
\mathrm{X} \pm \mathrm{SD}\end{array}$ & $\begin{array}{c}\text { Control GP } \\
\mathrm{X} \pm \mathrm{SD}\end{array}$ & $\begin{array}{c}t- \\
\text { value }\end{array}$ & $\begin{array}{c}p- \\
\text { value }\end{array}$ & $\begin{array}{c}\text { Study GP } \\
\mathrm{X} \pm \mathrm{SD}\end{array}$ & $\begin{array}{c}\text { Control GP } \\
\mathrm{X} \pm \mathrm{SD}\end{array}$ & $\begin{array}{c}t- \\
\text { value }\end{array}$ & $\begin{array}{c}p- \\
\text { value }\end{array}$ \\
\hline Fasting blood glucose & $243.90 \pm 8.13$ & $244.09 \pm 6.92$ & 0.056 & 0.955 & $200.81 \pm 8.60$ & $243.18 \pm 7.60$ & 12.24 & $0.0001 *$ \\
\hline Post prandil blood glucose & $364.27 \pm 41.04$ & $360.90 \pm 35.69$ & -0.2 & 0.83 & $321.18 \pm 33.50$ & $361.81 \pm 35.14$ & 2.77 & $0.0001 *$ \\
\hline
\end{tabular}




\section{Discussion}

Recently, there is a large body of scientific literature strongly supporting the role of HIIT as an effective cardiovascular exercise strategy in improving cardiorespiratory function and reducing risk factors of CVD. The objective of this study was to determine the effect of high intensity interval training on blood glucose in patients with type 2 diabetes. This study found that there was significant decrease in fasting and post prandial blood glucose in the study group.

This study was conducted on 40 type 2 diabetic subjects who were volunteered to participate in the study, their ages ranged from 45 to 55 years, and they were selected from outpatient clinic of Kasr El-Aini, Cairo University.

The patients were assigned into two groups equal in number: The first group (Group A), consisted of 20 patients, who practiced high intensity interval training for 12 weeks in addition to their optimized hypoglycemic medications. The second group (Group B), consisted of 20 patients, who received their optimized hypoglycemic medications.

This study suggested that both medical treatment and high intensity interval training caused significant reduction in fasting and post prandial blood glucose in study group after 12 weeks. The percentage of improvement was $\downarrow 17.66 \%$ for fasting blood glucose while it was $\downarrow 11.82 \%$ for two hours post prandial blood glucose. But there were no significant difference in control group pre and post three months. Percentage of change was $0.37 \%$ for fasting blood glucose or while it was $0.25 \%$ for post prandial blood glucose.

The results of this study came in agreement with the study of Winding et al., [12], who observed a reduction in glycated hemoglobin HbA1c and fasting glucose in the HIIT group, indicating that endogenous glucose production was affected in the group performing HIIT. The lower endogenous glucose appearance induced by HIIT was predominantly of hepatic origin. Lower endogenous glucose production after exercise training in T2D.

Moreover, Heiston et al., [13] approved that Insulin resistance in metabolic and vascular tissues is paramount to the regulation of circulating glucose and increases risk of T2D and Cardiovascular disease. Imbalances between exercise energy expenditure and energy intake are principle drivers of this "cross-talk" between organs that promote systemic and local inflammation for decreased insulin signaling.

In addition, Grace et al., [14] stated that physical activity represents a natural strong antiinflammatory and metabolism-improving strategy with minor side effects, this is likely to be true in people with T2DM undertaking aerobic training, even in water can to reduce glucose levels in this patient group.

Rynders et al., [15] concluded that acute HIIT decreases the postprandial glycemic and insulinemic responses to an oral glucose load. Furthermore, both moderate and HIIT improved insulin sensitivity $(51 \%-85 \%)$. Long-term training interventions will be required to investigate the effects of HIIT on glycemic excursion and whether HIIT results in a reduced conversion of prediabetes to DM2 that was coincided with this study.

Results achieved by Misra et al., [16] who stated that that Moderate-intensity Progressive Resistanceexercise Training (PRT) for 3 months resulted in significant improvement in insulin sensitivity, glycemia, lipids, and truncal and peripheral Subcutaneous Adipose Tissue (SCAT) in patients with type 2 diabetes. Resistance training should be an integral part of exercise regimen in Asian Indians with type 2 diabetes.

Also Karstoft and Pedersen, [17] came in the same line of this study as they compared aerobic interval with continuous training over 12 weeks in subjects with the metabolic syndrome they showed the interval training regimes are superior in improving metabolic parameters compared with continuous training regimes, or they show improvements equal to continuous regimes but with a lower training volume. In that respect, we have shown that aerobic interval walking training is superior to continuous walking training matched for volume, energy expenditure and mean intensity, for improving body composition, physical fitness, glycemic control and peripheral glucose disposal in patients with T2DM both acutely and after a long-term training intervention.

Furthermore, Mahmoudi et al., [18] showed that eight weeks of high interval training lead to a significant decrease in blood plasma glucose. Sports activities increase the number of glucose carriers and, as a result, increase the entrance of sugars into muscle cells and the consumption of sugars. Sports activities have an insulin-like effect and send a lot of glucose into the cell to spend on energy production. In this study, blood glucose levels in the diabetic group were significantly 
lower than that of the diabetic control group and diabetic patients who recieved metformin which suggested that intense activity may be a good alternative instead of medication to reduce glucose.

\section{Conclusion:}

From the results of this study we concluded that high intensity interval training has a positive effect on decreasing the elevated fasting and post prandial blood glucose in type 2 diabetic patients, consequently it helps in the management of type 2 diabetes.

\section{References}

1- MADMOLI M., DEHCHESHMEH Z.M., RAFI A., KORD Z., MOBAREZ F. and DARABIYAN P.: The rate of some complications and risk factors of diabetes in diabetic patients: Study on cases of 3218 diabetic patients. Medical Science, 23 (95): 63-8, 2019.

2- BELLOU V., BELBASIS L., TZOULAKI I. and EVANGELOU E.: Risk factors for type 2 diabetes mellitus: An exposure-wide umbrella review of meta-analyses. PloS one, 13 (3): e0194127, 2018.

3- ANDERSSON T., AHLBOM A. and CARLSSON S.: Diabetes prevalence in Sweden at present and projections for year 2050. PloS one, 10 (11), 2015.

4- NIKSERESHT A., SH F.H., SOLHJOO K. and KARGAR JAHROMY H.: Effect of maximum activity on the immune system cells in diabetic rats. Journal of Jahrom University of Medical Sciences, 10 (4): 43, 2013.

5- GORDON A.D., BISWAS S., FENG B. and CHAKRABARTI S. MALAT1: A regulator of inflammatory cytokines in diabetic complications. Endocrinology, diabetes \& metabolism, 1 (2), e00010. Batacan, Batacan, R.B., Duncan, M.J., 2018.

6- FERIOLI M., ZAULI G., MAIORANO P., MILANI D., MIRANDOLA P. and NERI L.M.: Role of physical exercise in the regulation of epigenetic mechanisms in inflammation, cancer, neurodegenerative diseases, and aging process. Journal of cellular physiology, 234 (9): 1485264, 2019.

7- GILLEN J.B., LITTLE J.P., PUNTHAKEE Z., TARNOPOLSKY M.A., RIDDELL M.C. and GIBALA M.J.: Acute high-intensity interval exercise reduces the postprandial glucose response and prevalence of hyperglycaemia in patients with type 2 diabetes. Diabetes, Obesity and Metabolism, 14 (6): 575-7, 2012.

8- SIGAL R.J., ARMSTRONG M.J., BACON S.L., BOULE N.G., DASGUPTA K., KENNY G.P. and RIDDELL M.C.:
Physical activity and diabetes. Canadian journal of diabetes, 42: S54-S63, 2018.

9- THENT Z.C., DAS S. and HENRY L.J.: Role of exercise in the management of diabetes mellitus: The global scenario. PloS one, 8 (11): e80436, 2013.

10- VAN DIJK J.W. and VANLOON L.J.: Exercise strategies to optimize glycemic control in type 2 diabetes: A continuing glucose monitoring perspective. Diabetes Spectrum, 28 (1): 24-31, 2015.

11- LITTLE J.P., GILLEN J.B., PERCIVAL M.E., SAFDAR A., TARNOPOLSKY M.A., PUNTHAKEE Z. and GIBALA M.J.: Low-volume high-intensity interval training reduces hyperglycemia and increases muscle mitochondrial capacity in patients with type 2 diabetes. Journal of applied physiology, 111 (6): 1554-60, 2011.

12- WINDING K.M., MUNCH G.W., IEPSEN U.W., VAN HALL G., PEDERSEN B.K. and MORTENSEN S.P.: The effect on glycaemic control of low-volume high-intensity interval training versus endurance training in individuals with type 2 diabetes. Diabetes, Obesity and Metabolism, 20 (5): 1131-9, 2018.

13- HEISON E.M. and MALIN S.K.: Impact of Exercise on Inflammatory Mediators of Metabolic and Vascular Insulin Resistance in Type 2 Diabetes. In Reviews on Biomarker Studies of Metabolic and Metabolism-Related Disorders (pp. 271-94). Springer, Cham, 2019.

14- GRACE A., CHAN E., GIALLAURIA F., GRAHAM P.L. and SMART N.A.: Clinical outcomes and glycemic responses to different aerobic exercise training intensities in type II diabetes: A systematic review and meta-analysis. Cardiovascular diabetology, 16 (1): 37, 2017.

15- RYNDERS C.A., WELTMAN J.Y., JIANG B., BRETON M., PATRIE J., BARRETT E.J. and WELTMAN A.: Effects of exercise intensity on postprandial improvement in glucose disposal and insulin sensitivity in prediabetic adults. The Journal of Clinical Endocrinology \& Metabolism, 99 (1): 220-8, 2014.

16- MISRA A., ALAPPAN N.K., VIKRAM N.K., GOEL K., GUPTA N., MITTAL K. and LLUTHEA K.: Effect of supervised progressive resistance-exercise training protocol on insulin sensitivity, glycemia, lipids, and body composition in Asian Indians with type 2 diabetes. Diabetes care, 31 (7): 1282-7, 2008.

17- KARSTOFT K. and PEDERSEN B.K.: Exercise and type 2 diabetes: Focus on metabolism and inflammation. Immunology and cell biology, 94 (2): 146-50, 2016.

18- MAHMOUDI Y., GHOLAMI M., NIKBAKHT H., EBRAHIM K. and BAKHTIYARI S.: Effect of High Intensity Interval Training with Metformin on Lipid Profiles and HbA1c in Diabetic Rats. Iranian Journal of Diabetes \& Obesity (IJDO), 10 (3), 2018. 


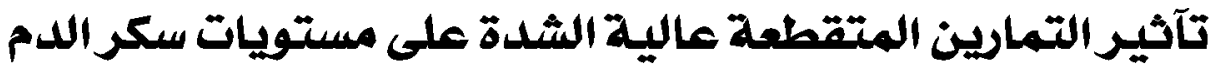

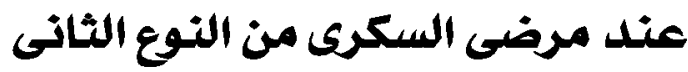

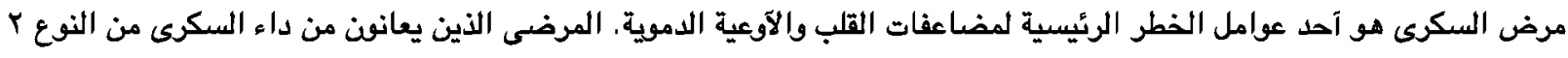

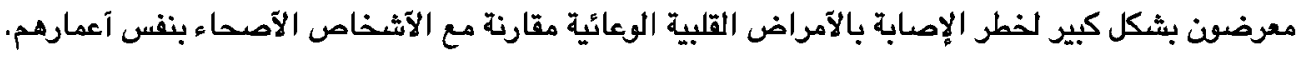

الهدف من الدراسة: تم تحديد تآثير التمارين المتقطعة عالية الشدة على مستويات السكر فى الدم فى النوع Y من مرض السكرى.

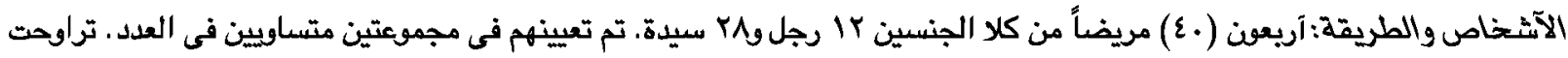

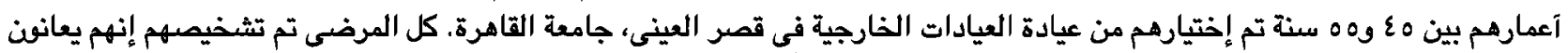

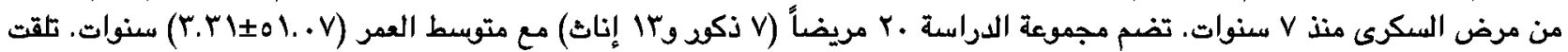

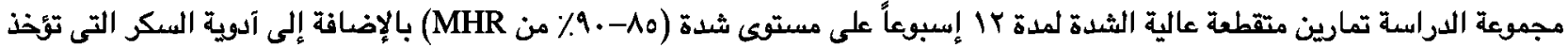

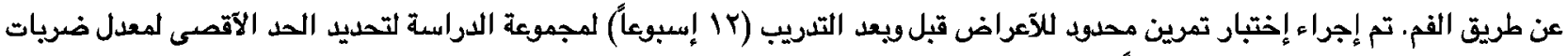

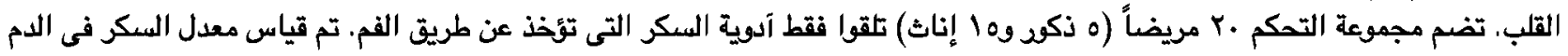
آثناء الصيام وبعد الإفطار بساعتين قبل بدء العلاج وبعد إنتهاء الجلسات فى كلا المجات المجوعتين. النتائج: بعد العلاج كان هناك تحسن كبير فى معدل السكر فى الدم آثناء الصيام وبعد الإفطار بساعتين. كان هناك إنخفاض كبير فى في

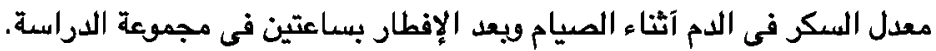

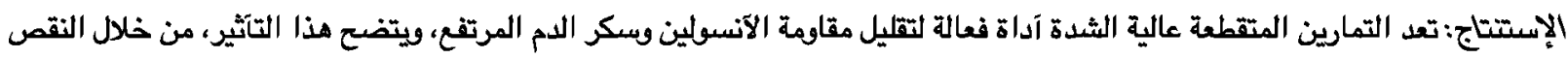

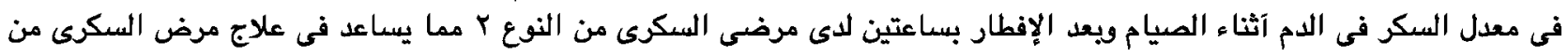

